This item was submitted to Loughborough's Research Repository by the author.

Items in Figshare are protected by copyright, with all rights reserved, unless otherwise indicated.

\title{
Willingness to adhere to current UK low-risk alcohol guidelines to potentially reduce dementia risk: A national survey of people aged 50 and over
}

\section{PLEASE CITE THE PUBLISHED VERSION}

https://doi.org/10.3233/JAD-181224

\section{PUBLISHER}

IOS Press $($ ) The authors

VERSION

AM (Accepted Manuscript)

\section{PUBLISHER STATEMENT}

The final publication is available at IOS Press through http://dx.doi.org/10.3233/JAD-181224.

\section{LICENCE}

CC BY-NC-ND 4.0

\section{REPOSITORY RECORD}

Oliveira, Deborah, Katy A. Jones, Reuben Ogollah, Semanur Ozupek, Eef Hogervorst, and Martin Orrell. 2019. "Willingness to Adhere to Current UK Low-risk Alcohol Guidelines to Potentially Reduce Dementia Risk: A National Survey of People Aged 50 and over". figshare. https://hdl.handle.net/2134/37982. 


\section{TITLE}

Willingness to adhere to current UK low-risk alcohol guidelines to potentially reduce dementia risk: A national survey of people aged 50 and over

\section{RUNNING TITLE}

Adhering to alcohol guidelines for dementia risk reduction

\section{AUTHORS AND AFFILIATIONS}

Deborah Oliveira $^{\mathrm{a}, \mathrm{b}}$; Katy A. Jones ${ }^{\mathrm{a}}$; Reuben Ogollah ${ }^{\mathrm{c}}$; Semanur Ozupek ${ }^{\mathrm{d}}$; Eef Hogervorst ${ }^{\mathrm{e}}$; Martin Orrell ${ }^{\mathrm{a}}$

a. Institute of Mental Health, Division of Psychiatry and Applied Psychology, School of Medicine, University of Nottingham, Innovation Park, United Kingdom

b. Department of Psychiatry, Federal University of Sao Paulo (UNIFESP), Brazil

c. Nottingham Clinical Trials Unit, Queen's Medical Centre, Nottingham, United Kingdom

d. School of Psychology, University of Nottingham, University Park Campus, Nottingham, United Kingdom

e. School of Sport, Exercise and Health Sciences, Loughborough University, Loughborough, United Kingdom

Corresponding author: Department of Psychiatry, School of Medicine, Federal University of Sao Paulo (UNIFESP). 925 Napoleão de Barros, 1st floor, 04024-002, Vila Clementino, São Paulo-SP, Brazil. Telephone:+55(11) 2149 0155. Email: oliveiradc.phd@gmail.com 


\section{ABSTRACT}

2 Background: People over 50 are increasing their alcohol intake, potentially increasing their 3 risk of dementia.

4 Objective: This study investigates whether people would be willing to adhere to current

5 United Kingdom (UK, "low-risk") alcohol guidelines to reduce dementia risk.

6 Methods: A national cross-sectional online survey recruited a non-probabilistic sample of

$7 \quad 3,948$ individuals aged 50 and over without dementia in the UK. Self-reported willingness to

8 comply with low-risk guidelines was predicted using multivariate logistic regression. Other

9 relevant self-reported variables included physical health, lifestyle, and current alcohol intake.

10 Results: Majority of the sample $(90 \%, n=3,527)$ reported drinking alcohol at least once a

11 month with $23 \%(n=795)$ exceeding the low-risk guidelines ( $>14$ units per week). A larger

12 proportion of men, those who were overweight, and people without a partner reported

13 drinking above the recommended level. Most people who consumed alcohol $(n=2,934$;

$1474.3 \%$ ) appeared willing to adhere to low-risk guidelines if they were told that their risk of

15 having dementia could be reduced. Increased willingness was found in women (OR 1.81; CI

16 1.47-2.23), in people who had at least one child (OR 1.36; CI 1.09-1.70) and those who slept

17 well (OR 1.45; CI 1.06-2.00). People who were obese (OR 0.72; CI 0.54-0.95), those who

18 drank alcohol above limits (OR 0.13; CI 0.11-0.16), and those who were smokers (OR 0.56;

19 CI 0.36-0.88) were less willing to adhere to current guidelines.

20 Conclusion: Men and people with more lifestyle risk factors for common chronic diseases

21 (e.g., smoking, obesity and excess alcohol consumption) are less willing to adhere to current

22 alcohol low-risk guidelines to reduce dementia risk.

23

24 KEYWORDS: Alcohol, Dementia, Disease prevention, Risk reduction, Older people 


\section{BACKGROUND}

2 In the UK, around $57 \%$ of the adult population reports drinking alcohol regularly [1]. "Baby

3 boomers" (people aged between 55 and 64) are "at-risk" for problems with alcohol intake as

4 they have shown a steady increase in weekly consumption, compared to a decrease in intake

5 by people aged 16-24 [1]. Crome and Rao [2] have called for a policy response to the over

650 s drinking habits based on increasing incidents of harm such as hospital admissions.

7

8 About a third of all cases of dementia might be attributed to modifiable risk factors, such as

9 alcohol consumption, diabetes, high blood pressure, and obesity [3]. Reducing these risk

factors in middle age could reduce the risk of developing dementia in later life [3]. Moderate to high consumption of alcohol is a risk factor for diabetes, heart disease, and dementia as it causes cumulative damage to vascular and brain structures [4-6]. Drinking 14-21 units a week increases the odds of right hippocampal atrophy (linked to dementia) three-fold while consuming over 30 units a week leads to the highest risk of hippocampal atrophy in a dosedependent manner [7]. A large meta-analysis of international studies found that a daily alcohol intake of $38 \mathrm{~g}$ (5 alcohol units) increased the risk of dementia [8].

Alcohol guidelines vary across the world and there is still no current consensus regarding socalled "safe" limits. Recent UK Government guidelines (hereafter referred to as "low-risk" guidelines) have reduced weekly alcohol intake for men (formerly 21 units per week), now recommending that both men and women drink no more than 14 units per week, spread their alcohol use over three or more days a week, and include alcohol-free days every week [9]. A recent meta-analysis has shown that drinking behaviour in later life is strongly associated with social engagement. However, there is scepticism among older people about the health risks of drinking alcohol [10]. Little is known about older people's attitudes to dementia risk or their 
1 willingness to moderate alcohol consumption. This study aimed to investigate the

2 characteristics of people aged 50 and over who would be willing to adhere to low-risk

3 guidelines to potentially reduce their risk of having dementia in the future.

4

\section{METHODS}

\section{$6 \quad$ Study design}

7 A UK-based cross-sectional online survey was undertaken from September 2017 to February

8 2018. The study is reported as per the Strengthening the Reporting of Observational Studies

9 in Epidemiology (STROBE) checklist [11].

\section{Recruitment}

Participants were aged 50 and over and had no dementia diagnosis (self-report). Potential participants were identified via social media and adverts. The Join Dementia Research network (a UK online platform for dementia research recruitment including mostly people

15 without dementia) and the UK National Institute for Health Research (NIHR) Portfolio, were also used. Before completing the survey, all individuals confirmed that they met the study

17 inclusion criteria and consented to take part in the research. Participants took approximately 1815 minutes to complete the anonymous survey.

21 As well as demographic information (area of residency; gender; age; highest qualification; 22 relationship status; number of children; working status; ethnic group; know or knew and cared 23 or care for someone with dementia), we measured several self-reported variables via online 24 survey (all selected based on international consensus for risk factors for dementia) [3]. 
1

2 Participants reported current health issues (e.g. diabetes, dyslipidaemia, high blood pressure)

3 and lifestyle factors including smoking. Using 5-point Likert scales, participants were also

4 asked about sleep quality; social and mental activity; stress; and depression.

5

$6 \quad$ Lifestyle

7 Alcohol consumption: Individuals were given examples of units of alcohol in common

8 beverages. Quantity and frequency of alcohol intake were based on the first two items of the

9 Alcohol Use Disorder Identification Test Consumption (AUDIT-C) [12]. The second item was

modified to reflect the number of units of alcohol consumed, rather than the number of drinks so that approximate alcohol intake for each person per week could be calculated. Individuals consuming $>14$ units were classed as exceeding current low-risk guidelines [9]. All participants were asked how likely they would be to adhere to low-risk guidelines if they were told this could reduce their risk of developing dementia (5-point Likert scale).

Physical activity: Participants were asked about their level of physical activity (5-point Likert scales) and the number of hours of exercise per week. People who reported doing at least 60 minutes of physical activity a week were asked how often their physical activity was moderate or vigorous.

Diet and Body Mass Index (BMI): Self-reported weight and height were collected to calculate BMI (weight $[\mathrm{kg}] /$ height $\left.^{2}[\mathrm{~m}]\right)(\mathrm{BMI}<18.5=$ underweight; 18.5 to $24.9=$ normal weight; 25.0 to 29.9 = overweight; $\geq 30=$ obese). Participants were asked how "healthy" they perceived their diet (5-point Likert scales) and how many portions of fruits/vegetables they consumed per day $(1$ portion $=$ a handful $)$. 


\section{Ethical approval}

3 The authors assert that all procedures contributing to this work comply with the ethical

4 standards of the relevant national and institutional committees on human experimentation and

5 with the Helsinki Declaration of 1975, as revised in 2008. Written informed consent was

6 obtained from all participants. All procedures involving human subjects/patients were

7 approved by the East Midlands - Nottingham Research Ethics Committee (IRAS project ID

8 177280; REC reference 16/EM/0044).

9

10

11

12

\section{Data analysis}

The primary outcome was participant's rating of willingness to follow low-risk alcohol guidelines to potentially reduce their risk of dementia (5-point Likert scale): (1) very likely, (2) quite likely, (3) not sure, (4) quite unlikely, and (5) very unlikely. Data were dichotomised for logistic regression analysis by combining categories (1) and (2) versus (3) to (5). All other variables collected were analysed as potential predictors of individuals' willingness to reduce alcohol consumption.

Number and percentage of (a) people having a drink containing alcohol in a typical month; (b) people exceeding the low-risk guideline; and (c) people who were willing to follow the lowrisk guideline were calculated. Logistic regression models were used to examine the association between the potential predictors and the primary outcome. The univariate association between each potential predictor and outcome was examined and those with p-values $<0.25$ were selected for inclusion in the multivariable model. Potential predictors were tested for the presence of multicollinearity. If multicollinearity was identified, one of the correlated predictors was dropped from the multivariable model. Manual backward elimination procedure was used 
1 to remove variables from the multivariable model until only variables with a p-value $<0.05$ were

2 retained in the final model. The total number of variables considered in the initial multivariable

3 logistic model complied with the rule of at least 10 events per variable [13] in order to avoid

4 possible overfitting. All analyses were performed in Stata 15. Odds ratios were presented with

5 the $95 \%$ confidence intervals.

6

\section{$7 \quad$ RESULTS}

8 A total of 3,948 individuals responded to the survey. They had a mean age of $62( \pm 8.0)$ and 9 were mostly female $(n=2,880 ; 73 \%)$. Of the 3,527 participants who reported drinking alcohol, it was calculated that $795(23 \%)$ exceeded the low-risk guideline on a typical week. Of the 1,060 males taking part in the study, 977 (92\%) reported having a drink containing alcohol in a typical month. Table 1 shows that a higher proportion of those drinking alcohol at least once a month $(n=3,527 ; 89.3 \%)$ were males $(n=977 ; 92.2 \%)$, slightly younger [mean age $62.2(8.0)$ vs. $63.3(7.5)]$, in a relationship $(n=2,663 ; 75.5 \%)$, educated to university level $(n=2,096$; $91.3 \%)$, and in good health $(n=3,245 ; 90.5 \%)$. A significantly larger proportion of males ( $n=362 ; 37.1 \%$ ), those without a partner $(n=657 ; 24.7 \%)$ and individuals who were overweight ( $n=325 ; 26.2)$ reported drinking above the low-risk guideline.

Most people $(n=2,934 ; 74.3 \%)$ who drank alcohol said they were likely to follow the low-risk guidelines if it meant their risk of developing dementia could be reduced. Table 2 shows demographic, health and lifestyle factors in relation to a willingness to follow low-risk guidelines. After adjusting for all other variables in the model, women (OR 1.81; CI 1.47-2.23), those with at least one child (OR 1.36; CI 1.09-1.70) and those with good sleep on some nights (OR 1.45; CI 1.06-2.00) or most nights (OR 1.42; CI 1.05-1.91) were more likely to follow low-risk alcohol guidelines. Being obese (OR 0.72; CI 0.54-0.95), consuming alcohol above 
1 the recommended limits (OR 0.13; CI 0.11-0.16) and being a smoker (OR 0.56; CI 0.36-0.88)

2 were associated with decreased willingness to adhere to low-risk guidelines.

3

\section{DISCUSSION}

\section{$5 \quad$ Main findings}

6 Most people who consumed alcohol (74\%) appeared willing to adhere to low-risk guidelines

7 if they were told that their risk of having dementia could be reduced. Most people $(90 \%)$

8 drank alcohol on a regular basis and a large proportion (23\%) reported to exceed the low-risk

9 guidelines ( $>14$ units per week). A significantly larger proportion of men, those who were overweight, and people without a partner reported drinking above the recommended limits. Increased willingness to adhere to the low-risk guidelines was found in women, in people who had at least one child, and in those who slept well. People who were obese, those who drank alcohol above limits, and smokers were less willing to adhere to current guidelines.

\section{Findings in the context of the current evidence}

The number of people aged 50 and over who drank alcohol in our study was higher than other UK estimates [14], but broadly corroborated general UK alcohol intake trends ( $92 \%$ of men and $88 \%$ of women reporting drinking regularly). The increased number of middle-aged and older women drinking regularly supports the closing gender gap $[15,16]$ and may reflect increasing social acceptability of alcohol use in women. In contrast to other work with older people (Meier [17] showed most frequent drinkers to be women aged 65-74, and men aged 75 and over), we found no significant differences between age and drinking habits or willingness to adhere to the low-risk guideline. Such contradicting evidence may be explained by the relatively larger number of educated people in our sample in relation to the general UK older population, as increased education has been associated with higher drinking patterns in older 
1 age [14]. This may also be because we had a comparatively younger sample (average age of

2 62) in comparison to most research with older people (age $\geq 65$ ), meaning that the views and

3 habits of relatively older groups (e.g., aged 70+) may not have been well represented.

4

5 Our findings support the idea that "healthy and wealthy" middle-aged and older people

6 consume alcohol most frequently. Health and wealth may affect drinking patters due to

7 increased exposure to social activities involving drinking, need to alleviate increasing stress,

8 and more disposable income to purchase alcohol, for example [10]. Our findings also support

9 some previous studies that found middle-aged and older adults who were single were drinking

10 more than those in partnerships [14]. Other work has shown, however, that people in

11 partnerships drink more frequently [18]. The reasons for such differing findings are currently

12 unclear but might suggest that some older couples may have alcohol habits embedded in their

13 relationships. Taking existing findings, and our work, it may also be that those in a

14 relationship may need guidance about moderating frequency, while people who are single

15 need advice about limiting quantity. The current lack of research examining relationship

16 patterns and alcohol intake in middle and later life, as oppose to the more established

17 evidence around drinking in early life and during pre- or post-divorce, limits further

18 interpretations of our findings.

20 Of concern was that those with other risk factors for dementia were self-reportedly less likely

21 to change their drinking behaviour and research has shown that the presence of more risk

22 factors contributes to a higher dementia risk due to the shared variance among these [3].

23 Female gender, parenthood, and good sleep quality seemed to play a role towards healthier

24 behaviour in relation to alcohol-related behaviour. People with children may feel more

25 responsibility to look after their health as a diagnosis of dementia could mean becoming 
1 dependent on their children or dying earlier or leaving their offspring behind. Middle-aged

2 and older women may be more acutely aware of the issues related to dementia and caregiving

3 than men, or more motivated by these issues [19]. However, further research is needed to

4 establish the plausibility of such arguments. Sleep disruptions become more frequent in later

5 life, with older people more frequently complaining about insomnia or multiple waking in

6 previous studies [20]. Alcohol is often used by older people to medicate sleep [21], thus self-

7 ascribed "poor sleepers" in the current study may have been less inclined to modify their

8 drinking patterns for believing that alcohol can help improve their sleep quality. Health

9 education about the negative effects on alcohol on sleep is needed to help reduce alcohol 10 consumption in later life.

11

12 The UK "low-risk" alcohol guidelines are relatively recent and for the first time they include 13 gender-neutral recommendations (14 units a week for both men and women) and abandon the 14 idea of "safe" drinking [9]. Consequently, younger generations started their drinking habits 15 when gender neutral and low-risk guidelines with a more conservative narrative about alcohol consumption had already been established. In contrast, people over 50 who took part in our

17 study had over 30 years of exposure to potentially confusing and contradictory messages 18 about how much alcohol is "safe", "sensible", "good" or "bad" for one's health. The concept 19 of "sensible drinking" was introduced in 1981, followed by the "safe" unit limits published in 20 1984, had allowed higher consumption for men compared to women [18 units a week for men 21 and 9 for women [22]]. Such historical changes may explain not only why men are more

22 likely to be drinkers and why women's drinking is increasing, but it may also explain why we 23 found men to be less willing to change their drinking behaviour [23]. Older men may have 24 more difficulties with changing alcohol-related behaviour due to several decades of heavier 25 drinking patterns reinforced by higher-unit guidelines available for them. 
2 Ideas about alcohol being good for your heart were introduced in the early 1990s, further

3 contributing to the confusion around the potential harm of alcohol to one's health and

4 potentially influencing patterns of heavier drinking in middle and later life. Both alcohol

5 consumption as a risk factor for brain disease and dementia are considered to be newsworthy

6 topics and are subject to frequent and potentially inaccurate reporting [24, 25]. For example,

7 recent studies reported by the media have portrayed conflicting messages about whether

8 "moderate drinking" is protective or a risk factor for dementia [[e.g. 26] and [7]]. Such

9 disparities may encourage people to continue to consume alcohol as usual and may make

\section{Implications}

Our findings have important implications for clinical practice and future research. Middleaged and older men and those who are obese, smokers or heavy drinkers may be less willing to adhere to the alcohol guidelines and should receive more attention from primary and secondary health care services. Individuals with such characteristics could benefit from motivational interviewing or brief counselling interventions to help them identify and implement gradual, but effective and permanent changes in lifestyle. There is moderatequality evidence that such strategies can be more effective than no treatment to reducing alcohol consumption [27]. Clinicians should be aware of the "social role" of alcohol and should try and identify the best ways by which alcohol consumption could be reduced whilst 
1 still maintaining any social activities that are meaningful to individuals. Older people who

2 have sleep problems might be using alcohol to medicate sleep and so awareness should be

3 raised regarding the negative effect of alcohol on sleep quality among these individuals.

$4 \quad$ Further research needs to be conducted regarding alcohol and sleep and on the relationship

5 between alcohol consumption and relationship status. More consistent and coherence

6 guidance across genders needs to be provided to the public in order to encourage them to

7 adhere to the low-risk guidelines, particularly to those who have other risk factors for

8 dementia.

\section{Strengths and weaknesses}

11 As it is the case of most surveys, this was a cross-sectional study and was limited by self-

12 report data and non-probabilistic sample, which can be less generalisable to the entire

13 population and less sensitive due to people's underestimations of their own alcohol intake

14 [28] or insight into their own physical health. Self-report of willingness to change lifestyle

15 may also have 'temporal' limitations as people's understandings of health risks and their

16 motivations to change lifestyle may vary according to people's mood, life experiences and

17 health knowledge, for example. However, the subjective assessment of other variables such

18 sleep quality can be as powerful as their objective measurement and contributed to the

19 robustness of our study [29]. Older people are likely to be the least informed about alcohol

20 units [23], though we attempted to address this by providing illustrations of the number of

21 units of alcohol in common beverages.

22

23 The large representation of women is a strength as less is known about older women's alcohol

24 consumption and attitudes towards it [16]. However, the study is limited by having fewer

25 men, who are more likely to be drinkers in later life [23]. Most people were highly educated 
1 and from a white European background and previous studies have shown that dementia risk

2 varies according to different ethnic groups and tends to be higher in less educated individuals

$3[14,30,31]$. Nevertheless, as alcohol consumption tends to be higher in highly educated and

4 wealthy people $[14,32]$, this study included those who are more likely to need advice about

5 alcohol.

6

7 In general, surveys like ours are often confounded by selection bias (white, higher educated etc). However, a future investigation should recruit a randomized sample to include a more representative sample (e.g. more people over 70, more men, a broader range of educational qualifications, and a more ethnically diverse population). This could help confirm and would allow for broader generalisation of the findings. Future studies should also attempt to use or develop standardised measurements of willingness to reduce alcohol intake for dementia risk reduction. One measure that could be used to assess people's general motivation to change lifestyle specifically for dementia risk reduction is the Motivation to Change Lifestyle and Health Behaviours for Dementia Risk Reduction (MCLHB-DRR), which has been developed and validated in Australia [33].

It is important to consider that people who completed the survey may have been those who are more likely to change behaviour as they have an interest in this topic than those who did not complete the survey. This means that the population of those who are less likely to change their alcohol intake may have been underrepresented in this study. Previous work examining change in risk behaviour has shown that long-term risk can be a weak driver of behaviour, with people tending to monitor their behaviour by certain and immediate pleasure [34]. It might therefore be unclear whether a person's perception of what they may do would match with future behaviour. 
1

2 The majority of middle-aged and older people were willing to adhere to low-risk guidelines if

3 they were told that their risk of having dementia could be reduced. Those who were most

4 reluctant may be at greatest need of health intervention. Gender, parental roles, and other

5 health behaviours, such as smoking, sleep patterns, weight management and amount of

6 alcohol intake, may influence willingness to follow alcohol guidelines. Although behaviour

7 change and risk calculation are complex and involve socioeconomic, psychological and

8 cultural factors, this study helped identify suggestive evidence of those who might be at the

9 highest risk for non-adherence to alcohol guidelines for dementia risk reduction. Future public 10 health actions should consider differences in willingness to change risk behaviour according to gender, sleep quality, parental roles, obesity, smoking status and amount of alcohol consumed in order to increase the sensitiveness of alcohol-related interventions.

\section{ACKNOWLEDGEMENTS}

This work was funded by the Alzheimer's Research UK. The funder had no role in study design, data collection and analysis, decision to publish, or preparation of the manuscript.

\section{CONFLICT OF INTEREST/DISCLOSURE STATEMENT}

DO has received funding from the Alzheimer's Research UK. MO has received grants from the ESRC, NIHR and EU Commission for dementia care research. All the other authors have no conflict of interest.

\section{REFERENCES}


1 [1] Office of National Statistics (2017) Adult drinking habits in Great Britain. Available

2 in: https://www.ons.gov.uk/releases/adultdrinkinghabitsingreatbritain2017 Accessed 3 April

32019.

4 [2] Crome I, Rao R (2011) Substance misuse and older people: Our Invisible Addicts.

5 Ment Health Subst Use 4, 267-269. [doi: http://dx.doi.org/10.1080/17523281.2011.611298]

6 [3] Livingston G, Sommerlad A, Orgeta V, Costafreda SG, Huntley J, Ames D, et al.

7 (2017) Dementia prevention, intervention, and care. Lancet 390, 2673-2734. [doi:

$8 \quad$ http://dx.doi.org/10.1016/S0140-6736\%2817\%2931363-6]

9 [4] Schwarzinger M, Pollock BG, Hasan OSM, Dufouil C, Rehm J (2018) Contribution of 10 alcohol use disorders to the burden of dementia in France 2008-13: a nationwide

11 retrospective cohort study. Lancet Public Health 3, e124-e32. [doi:

12 https://doi.org/10.1016/S2468-2667(18)30022-7]

13 [5] Welch KA (2017) Alcohol consumption and brain health. BMJ 357, 1-2. [doi:

14 https://doi.org/10.1136/bmj.j2645]

15 [6] World Health Organization (2017) Global action plan on the public health response to 16 dementia 2017-2025. Available in:

17 https://www.who.int/mental_health/neurology/dementia/action_plan_2017_2025/en/

$18 \quad$ Accessed 3 April 2019

19 [7] Topiwala A, Allan CL, Valkanova V, Zsoldos E, Filippini N, Sexton C, et al. (2017)

20 Moderate alcohol consumption as risk factor for adverse brain outcomes and cognitive

21 decline: longitudinal cohort study. BMJ 357, 1-20. [doi: https://doi.org/10.1136/bmj.j2353]

22 [8] Xu W, Wang H, Wan Y, Tan C, Li J, Tan L, et al (2017) Alcohol consumption and 23 dementia risk: a dose-response meta-analysis of prospective studies. Europ J Epidemiol 32,

24 31-42. [doi: https://doi.org/10.1007/s10654-017-0225-3] 
1 [9] Department of Health (2016) UK Chief Medical Officers ' Low Risk Drinking

2 Guidelines. Available in:

3 https://assets.publishing.service.gov.uk/government/uploads/system/uploads/attachment_data/

4 file/545937/UK_CMOs_report.pdf Accessed 3 April 2019.

5 [10] Kelly S, Olanrewaju O, Cowan A, Brayne C, Lafortune L (2018) Alcohol and older

6 people: A systematic review of barriers, facilitators and context of drinking in older people

7 and implications for intervention design. PloS one 13, 1-14. [doi:

8 https://doi.org/10.1371/journal.pone.0191189].

9 [11] von Elm E, Altman DG, Egger M, Pocock SJ, Gøtzsche PC, Vandenbroucke JP (2007)

10 Strengthening the reporting of observational studies in epidemiology (STROBE) statement:

11 guidelines for reporting observational studies. BMJ 335, 806-808. [doi:

12 [https://doi.org/10.1136/bmj.39335.541782.AD]

13 [12] Bush K, Kivlahan DR, McDonell MB, Fihn SD, Bradley KA (1998) The audit alcohol 14 consumption questions (audit-c): An effective brief screening test for problem drinking. Arch

15 Intern Med 158, 1789-1795. [doi: https://doi.org/10.1001/archinte.158.16.1789]

16

17

18

19

20

21

22

23

24

25

[13] Peduzzi P, Concato J, Kemper E, Holford TR, Feinstein AR (1996) A simulation study

of the number of events per variable in logistic regression analysis. J Clin Epidemiol 49, 1373-1379. [doi: https://doi.org/10.1016/S0895-4356(96)00236-3]

[14] Holdsworth C, Mendonça M, Pikhart H, Frisher M, de Oliveira C, Shelton N (2016) Is regular drinking in later life an indicator of good health? Evidence from the English Longitudinal Study of Ageing. J Epidemiol Community Health 70, 764-770. [doi: https://doi.org/10.1136/jech-2015-206949]

[15] Institute of Alcohol Studies (2017) Women and alcohol. London,UK. Available in: http://www.ias.org.uk/Alcohol-knowledge-centre/Alcohol-and-women.aspx Accessed 3 April 2019. 
1 [16] Milic J, Glisic M, Voortman T, Borba LP, Asllanaj E, Rojas LZ, et al. (2018)

2 Menopause, ageing, and alcohol use disorders in women. Maturitas 111, 100-109. [doi:

3 https://doi.org/10.1016/j.maturitas.2018.03.006]

4 [17] Meier PS (2010) Polarized Drinking Patterns and Alcohol Deregulation: Trends in

5 alcohol consumption, harms and policy: United Kingdom 1990 - 2010. Nordic Studies on

6 Alcohol and Drugs 27, 383-408. [doi: https://doi.org/10.1177/145507251002700501].

7 [18] Liang W, Chikritzhs T (2012) Brief report: marital status and alcohol consumption

8 behaviours. J Substance Use 17, 84-90. [doi: https://doi.org/10.3109/14659891.2010.538463]

9 [19] Bartlett R, Gjernes T, Lotherington A-T, Obstefelder A (2016) Gender, citizenship and

10 dementia care: a scoping review of studies to inform policy and future research. Health Soc

11 Care Community 26, 14-26. [doi: https://doi.org/10.1111/hsc.12340].

12 [20] Morgan E, Schumm LP, McClintock M, Waite L, Lauderdale DS (2017) Sleep

13 Characteristics and Daytime Cortisol Levels in Older Adults. Sleep 40, 1-11. [doi:

14 https://10.1093/sleep/zsx043]

15 [21] Aldrich M (1998) Effects of alcohol on sleep. In: Alcohol Problems and Aging.

16 Research Monograph 33: National Institute on Alcohol Abuse and Alcoholism, Gomberg E,

17 Hegedus A, Zucker R, Bethesda M, eds. NIH Publication No. 98-4163, p. 98-4163. Available

18 in: https://pubs.niaaa.nih.gov/OrderForm/EncForm/Monographs Accessed 3 April 2019.

19 [22] House of Commons (2011) Science and Technology Committee. Alcohol guidelines.

20 Eleventh Report of Session 2010-12. Available in:

21 https://publications.parliament.uk/pa/cm201012/cmselect/cmsctech/1536/1536.pdf Accessed

$22 \quad 3$ April 2019.

23 [23] Holley-Moore G, Beach B (2016) Drink Wise, Age Well: Alcohol Use and the Over

2450 s in the UK. London: International Longevity Centre. Available in: 
1 https://drinkwiseagewell.org.uk/wp-content/uploads/2016/01/Drink-Wise-Age-Well-Alcohol-

2 Use-and-the-over-50s-Report-2.pdf Accessed 3 April 2019.

3 [24] Patterson C, Emslie C, Mason O, Fergie G, Hilton S (2016) Content analysis of UK

4 newspaper and online news representations of women's and men's 'binge' drinking: a

5 challenge for communicating evidence-based messages about single-episodic drinking? BMJ

6 Open 6, 1-9. [doi: http://dx.doi.org/10.1136/bmjopen-2016-013124]

7 [25] Brookes G, Harvey K, Chadborn N, Dening T (2018) “Our biggest killer”: multimodal

8 discourse representations of dementia in the British press. Social Semiotics 28, 371-395. [doi:

9 http://dx.doi.org/10.1080/10350330.2017.1345111].

10 [26] Sabia S, Fayosse A, Dumurgier J, Dugravot A, Akbaraly T, Britton A, et al. (2018)

11 Alcohol consumption and risk of dementia: 23 year follow-up of Whitehall II cohort study.

12 BMJ 362, 1-11 [doi: https://doi.org/10.1136/bmj.k2927]

13 [27] Kaner EFS, Beyer FR, Muirhead C, Campbell F, Pienaar ED, Bertholet N, et al.

14 (2018) Effectiveness of brief alcohol interventions in primary care populations. Cochrane

15 Database of Systematic Reviews 2, CD004148 [doi:

16 https://10.1002/14651858.CD004148.pub4]

17 [28] Boniface S, Kneale J, Shelton N (2013) Actual and Perceived Units of Alcohol in a

18 Self-Defined "Usual Glass" of Alcoholic Drinks in England. Alcoholism, Clinical and

19 Experimental Research 37, 978-983. [doi: https://10.1002/10.1111/acer.12046]

20 [29] Lichstein KL (2017) Insomnia identity. Behaviour Research and Therapy 97, 230-241.

21 [doi: https://doi.org/10.1016/j.brat.2017.08.005]

22 [30] Garcia MA, Saenz J, Downer B, Wong R (2018) The role of education in the

23 association between race/ethnicity/nativity, cognitive impairment, and dementia among older

24 adults in the United States. Demographic Research 38, 155-168. [doi:

25 https://doi.org/10.4054/DemRes.2018.38.6] 
1 [31] Rodriguez FS, Aranda MP, Lloyd DA, Vega WA (2018) Racial and Ethnic Disparities

2 in Dementia Risk among Individuals with Low Education. Am J Geriatric Psychiatry 26, 966-

3976 [doi: https://doi.org/10.1016/j.jagp.2018.05.011]

4 [32] Iparraguirre J (2015) Socioeconomic determinants of risk of harmful alcohol drinking

5 among people aged 50 or over in England. BMJ Open 5, 1-14 [doi:

6 http://dx.doi.org/10.1136/bmjopen-2015-007684]

7 [33] Kim S, Sargent-Cox K, Cherbuin N, Anstey KJ (2014). Development of the

8 motivation to change lifestyle and health behaviours for dementia risk reduction scale.

9 Dement Ger Cog Disord 4, 172-183. [doi: http://dx.doi.org/10.1159/000362228]

10 [34] Marteau TM, Hollands GJ, Fletcher PC (2012) Changing Human Behavior to Prevent

11 Disease: The Importance of Targeting Automatic Processes. Science 337, 1492-1495. [doi:

12 http://dx.doi.org/10.1126/science.1226918]

13 
Table 1. Characteristics of those having a drink containing alcohol and who drink beyond "low-risk" limit

Drinking beyond limit typical month

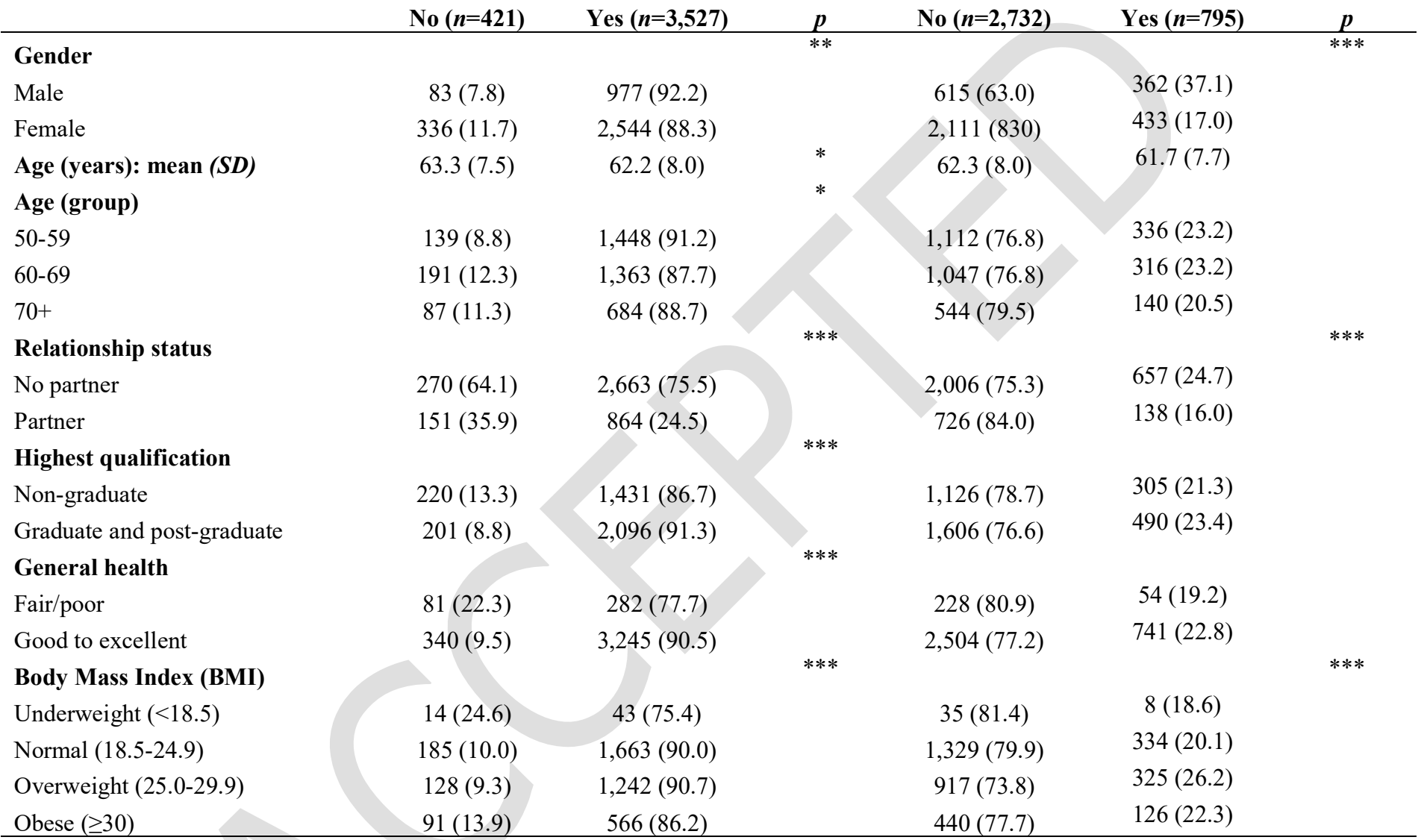


Table 2. Characteristics of individuals who drink alcohol who would follow UK Government guidelines on low risk intake and unadjusted and adjusted odds ratios of association with willingness to follow low-risk alcohol guidelines

\begin{tabular}{|c|c|c|c|c|}
\hline Variables & $\begin{array}{c}\text { Quite/very unlikely to } \\
\text { follow low-risk levels } \\
(n=1,014 ; 25.7 \%) \\
\end{array}$ & $\begin{array}{c}\text { Very/quite likely to follow } \\
\text { low-risk levels } \\
(n=2,934 ; 74.3 \%)\end{array}$ & $\begin{array}{c}\text { Unadjusted (Univariate)* } \\
\text { OR (95\% CI) }\end{array}$ & $\begin{array}{c}\text { Adjusted } \dagger \\
\text { OR (95\% CI) }\end{array}$ \\
\hline \multicolumn{5}{|l|}{ Gender } \\
\hline Male & $265(27.1)$ & $712(72.9)$ & 1 & 1 \\
\hline Female & $326(12.8)$ & $2,218(87.2)$ & $2.53(2.11,3.04)$ & $1.81(1.47,2.23)$ \\
\hline Age (years): mean (SD) & $61.8(7.7)$ & $62.3(8.0)$ & $1.01(0.99,1.02)$ & - \\
\hline \multicolumn{5}{|l|}{ Relationship status } \\
\hline No partner & $144(6.7)$ & $720(83.3)$ & 1 & - \\
\hline Partner & $449(16.9)$ & $2,214(83.1)$ & $0.99(0.80,1.21)$ & - \\
\hline \multicolumn{5}{|l|}{ Highest qualification } \\
\hline Non-graduate & $217(15.2)$ & $1,214(84.8)$ & 1 & - \\
\hline Graduate and post-graduate & $376(17.9)$ & $1,720(82.1)$ & $0.82(0.68,0.98)$ & - \\
\hline \multicolumn{5}{|l|}{ General health } \\
\hline Fair/poor & $56(19.9)$ & $226(80.1)$ & 1 & - \\
\hline Good to excellent & $537(16.6)$ & $2,708(83.5)$ & $1.25(0.92,1.70)$ & - \\
\hline \multicolumn{5}{|l|}{ Body Mass Index (BMI) } \\
\hline Underweight & $7(16.3)$ & $36(83.7)$ & $0.87(0.38,1.98)$ & $0.82(0.34,2.00)$ \\
\hline Normal & $241(14.5)$ & $1,422(85.5)$ & 1 & 1 \\
\hline Overweight & $234(18.8)$ & $1,008(81.2)$ & $0.73(0.60,0.89)$ & $0.88(0.71,1.10)$ \\
\hline Obese & $109(19.3)$ & $457(80.7)$ & $0.71(0.55,0.91)$ & $0.72(0.54,0.95)$ \\
\hline \multicolumn{5}{|l|}{ Currently employed } \\
\hline No & $283(16.2)$ & $1,464(83.3)$ & 1 & - \\
\hline Yes & $310(17.4)$ & $1,470(82.6)$ & $0.92(0.77,1.09)$ & - \\
\hline \multicolumn{5}{|l|}{ Ethnic group } \\
\hline Non-white & $13(14.8)$ & $75(85.2)$ & 1 & - \\
\hline White & $580(16.9)$ & $2,859(83.1)$ & $0.85(0.47,1.55)$ & - \\
\hline Has children & & & & - \\
\hline No & $172(20.0)$ & $688(80.0)$ & 1 & 1 \\
\hline
\end{tabular}


Yes

Ever known someone living with dementia

No

Yes

Ever been a carer for someone with dementia No

Yes (family/informal)

Yes (professional)

Yes (professional \& family)

\section{Co-morbidity}

No disease/disorder

1 disease/disorder

2 or more diseases/disorder

\section{Weekly alcohol consumption}

Low risk (1 to 14 units)

At risk (>14 units)

Current smoker

No

Yes

Physical activity

Not active

Moderately/very active

Portions of fruit consumed per day

0-2 portions

3-4 portions

5 or more portions

Sleep well

Almost never/never

Some nights

Always/most nights
$419(15.8)$

$83(18.8)$

$510(16.5)$

$240(18.3)$

$208(15.2)$

34 (14.2)

$28(17.0)$

$320(17.5)$

$119(16.2)$

154 (16.0)

237 (8.7)

$356(44.8)$

555 (16.3)

38 (30.2)

125 (17.1)

468 (16.7)

124 (19.9)

$267(17.1)$

$202(15.0)$

$90(21.5)$

$196(16.0)$

307 (16.3)
359 (81.2)

$2,575(83.5)$

1,069 (81.7)

$1,164(84.8)$

205 (85.8)

$137(83.0)$

$1,510(82.5)$

$615(83.8)$

$809(84.0)$

2,495 (91.3)

439 (5.2)

$2,846(83.7)$

88 (69.8)

607 (82.9)

$2,327(83.3)$

$500(80.1)$

1,292 (82.9)

$1,142(85.0)$

$329(78.5)$

$1,027(84.0)$

$1,578(83.7)$

\section{- 1}

$1.17(0.90,1.51)$

$1.26(1.03,1.54)$

$1.35(0.92,2.00)$

$1.10(0.71,1.69)$

\section{1}

$1.10(0.87,1.38)$

$1.11(0.90,1.37)$

1

$0.12(0.09,0.14)$

1

$0.45(0.31,0.67)$

$1.02(0.82,1.27)$

$1.20(0.95,1.52)$

$1.40(1.10,1.80)$

1

$1.43(1.08,1.89)$

$1.41(1.08,1.83)$
$0.13(0.11,0.16)$

$0.56(0.36,0.88)$
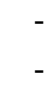

$-$

$1.45(1.06,2.00)$

$1.42(1.05,1.91)$ 


\section{Feel depressed}

Never/rarely

\begin{tabular}{lccc}
$305(16.5)$ & $1,547(83.5)$ & 1 & - \\
$258(16.9)$ & $1,268(83.1)$ & $0.97(0.81,1.16)$ & - \\
$30(20.1)$ & $119(79.9)$ & $0.78(0.51,1.19)$ & - \\
& & & - \\
$203(18.2)$ & $910(81.8)$ & 1 & - \\
$321(15.6)$ & $1,731(84.4)$ & $1.20(0.99,1.46)$ & - \\
$69(19.1)$ & $293(80.9)$ & $0.95(0.70,1.28)$ & - \\
& & & - \\
$143(17.9)$ & $658(82.2)$ & 1 & - \\
$450(16.5)$ & $2,276(83.5)$ & $1.10(0.89,1.35)$ & \\
$51(15.6)$ & $275(84.4)$ & 1 & \\
$542(16.9)$ & $2,659(83.1)$ & $0.91(0.67,1.24)$ & \\
\hline
\end{tabular}

\section{Sometimes}

Always/most times

\section{Feel stressed}

Never/rarely

\section{Sometimes}

$542(16.9)$

Very/quite mentally active

\section{Social activity}

Not socially active

Very/quite socially active

\section{Mental activity}

* Univariate association between each variable and willingness to follow UK Government low-risk level.

$\uparrow$ Adjusted for all the other variables in the final model. All the variables in the univariate model except relationship status, job status, ethnicity, knowing someone living with dementia, number of health problems, physical activity, depression and social activity were significant $(p<0.25)$ and were included in the initial multivariable model. Only significant variables $(p<0.05)$ are presented in the final multivariable model.

1

$S D=$ Standard Deviation 